\title{
ANÁLISE DE VIABILIDADE TÉCNICA PARA O DESENVOLVIMENTO DE UM APLICATIVO PARA O COMÉRCIO ELETRÔNICO NO RAMO DE ALUGUÉIS
}

Antonio Leonardo Barbosa de Souza (barbosaleo05@gmail.com)- Grupo de Estudos e Pesquisa em Inovação e Tecnologia Aplicadas à Educação de Ensino Superior (GEPITEES)- Universidade Federal de Alagoas.

Ana Carolina Faria (anacarolina.cintrafaria@gmail.com)- Grupo de Estudos e Pesquisa em Inovação e Tecnologia Aplicadas à Educação de Ensino Superior (GEPITEES)- Universidade de Brasília.

Anderson Andrade (anderson_andreade_@outlook.com)- Grupo de Estudos e Pesquisa em Inovação e Tecnologia Aplicadas à Educação de Ensino Superior (GEPITEES) - Centro Universitário de Desenvolvimento do Centro-Oeste.

Thiago Pereira (xtremearts.tg@gmail.com)- Grupo de Estudos e Pesquisa em Inovação e Tecnologia Aplicadas à Educação de Ensino Superior (GEPITEES) - Centro Universitário de Desenvolvimento do Centro-Oeste.

\section{RESUMO}

Para a criação de novos produtos, uma boa estruturação do Processo de Desenvolvimento de Produto (PDP) traz consigo vantagem competitiva e benefícios como maior capacidade de diversificação dos produtos, potencial para a transformação de novas tecnologias em novos produtos, e menores custos dos produtos desenvolvidos. O celular mudou a forma de relacionamento entre as pessoas e um dos produtos que surgiram com a popularização dos smartphones foram os aplicativos. O presente artigo realiza uma análise da viabilidade técnica de um aplicativo mobile a ser desenvolvido sob a perspectiva de PDP para o ramo de aluguéis. Concebendo o protótipo do app à luz do planejamento estratégico e da modelagem da aplicação mobile. Para as fases iniciais do percurso metodológico de análise da viabilidade técnica do aplicativo fez-se uso do modelo unificado do Processo de Desenvolvimento de Produto, da pesquisa aplicada, de ordem exploratória e do método de modelagem e simulação. Observouse que o aplicativo tem potencial para o mercado além de possuir características inovadoras, tendo em vista o ineditismo de funcionalidades, ferramentas e oferecimento de serviços em uma única plataforma. 
Palavras chave: Processo de Desenvolvimento de Produto; Aplicativo; Mercado de aluguéis; Inovação; Protótipo. 


\section{INTRODUÇÃ̃}

Em se tratando de inovação o desenvolvimento econômico está diretamente relacionado a ela, impactando o estado de equilíbrio do mercado capitalista (SCHUMPETER ;1988). Para a criação de novos produtos, uma boa estruturação do Processo de Desenvolvimento de Produto (PDP) traz consigo vantagem competitiva como também alguns outros benefícios, por exemplo; maior capacidade de diversificação dos produtos, potencial para a transformação de novas tecnologias em novos produtos, melhores parcerias, menores custos dos produtos desenvolvidos e menor tempo para o desenvolvimento de novos produtos (JUGEND, 2006, p. $8)$.

Um exemplo de produto que tem mudado a forma de relacionamento entre as pessoas é o telefone celular, que inicialmente foi criado para ser apenas um dispositivo para conversação por voz, entretanto, com o avanço da tecnologia e a evolução das gerações da telefonia celular, esse dispositivo passou a integrar a rede de celular com a rede de dados, como a internet, ampliando sua capacidade de processamento e de comunicação (FIGUEIREDO; NAKAMURA, 2003). Segundo o estudo da McKinsey Global Institute (2013), mais de 1,1 bilhão de pessoas possuem smartphones e tablets e estima-se que em 2025 , mais ou menos $80 \%$ de todas as conexões na internet deverão ser realizadas primariamente via dispositivos móveis. Diante do exposto, o presente artigo realiza uma análise da viabilidade técnica de um aplicativo mobile a ser desenvolvido sob a perspectiva de PDP para o ramo de aluguéis. Concebendo o protótipo do app à luz do planejamento estratégico e da modelagem da aplicação mobile.

\section{INOVAÇÃO E APLICATIVOS MOBILES}

O conceito de inovação foi originalmente formulado por Schumpeter (1957), que afirma serem os empresários, enquanto base da classe capitalista, fundamentais para o desenvolvimento econômico, pois são eles que estão sempre em busca da inovação. Para Schumpeter, "inovação" significa "fazer as coisas diferentemente no reino da vida econômica".

No contexto de surgimento das inovações mapeadas por Moricochi e Gonçalves (1994), destaca-se:

a) introdução de um novo bem não familiar aos consumidores ou então de nova qualidade de um certo bem; 
b) abertura de um novo mercado, ou seja, um mercado em que o produto de determinada indústria nunca tivera acesso antes, independentemente deste mercado ter ou não existido anteriormente;

c) reorganização de uma indústria qualquer, como a criação ou a ruptura de uma posição de um monopólio.

Ainda que denominações e atributos tenham se desdobrado das definições originalmente propostas por Schumpeter, para este trabalho é necessário olhar para o conceito que caracteriza inovação como novos produtos, novas tecnologias; novos processos, que pretendem tipicamente agilizar processos. Porque é a partir das noções de mudança de paradigma e mercado, que surgem os smartphones e consequentemente os aplicativos móveis (CHAUDHARY; SHARMA, 2015).

Para a indústria dos telefones móveis os smartphones foram o que Clayton Christensen (1997), chama de inovação disruptiva, conceito que deu origem a uma solução mais eficiente do que as existentes no mercado além de afetar significativamente a dinâmica empresarial.

O celular mudou a forma de relacionamento entre as pessoas e um dos produtos que surgiram com a popularização dos smartphones foram os aplicativos, também chamados de apps (GERMANO; SOUZA, 2016; DE GUSTA, 2012).

Um levantamento feito pela empresa App Annie aponta um aumento de $22 \%$ nos gastos com aplicativos nos três primeiros meses de 2018, somadas ambas as lojas digitais da Apple e Google. Ao todo, foram US\$ 18,4 bilhões no período. Ressaltando que os aplicativos para dispositivos móveis, proporcionam uma nova forma de comercializar não só produtos, como também serviços (WAKKA, 2018, p.1).

\section{METODOLOGIA}

O modelo unificado do Processo de Desenvolvimento de Produtos (PDP) de Rozenfeld et.al., (2006) descreve as atividades, recursos, informações, fases, responsabilidades e outras possíveis dimensões do processo de desenvolvimento do produto. O referido modelo é voltado principalmente para empresas de manufatura de bens de consumo duráveis e de capital, além de ser baseado em um framework e oferecer ferramentas de suporte de modelagem. 
Neste sentido, para as fases iniciais do percurso metodológico de análise da viabilidade técnica do aplicativo fez-se uso do modelo unificado do PDP. E no que diz respeito à classificação, esta pesquisa seguiu a orientação metodológica e os procedimentos para investigação científica de Turrioni e Mello (2012), conforme exposto a seguir:

a. Quanto à natureza: a pesquisa é aplicada, pois a análise da viabilidade técnica está sendo realizada com a intenção de desenvolver o aplicativo.

b. Quanto ao objetivo: pode-se classificá-los como de natureza exploratória, uma vez que foram realizadas análises de exemplos que estimulam a compreensão, com vistas a desenvolver uma ferramenta móvel para o ramo de aluguéis.

c. Quanto à abordagem: a pesquisa possui natureza qualitativa, pois as informações serão tratadas de forma descritiva, não podendo ser quantificáveis.

d. Quanto ao método: foram utilizadas a modelagem e simulação uma vez que o desejo era experimentar e simular, através de um protótipo e de um conjunto de características de análise de viabilidade técnica, o aplicativo. A fim de determinar como este sistema responderá a modificações que lhe são propostas.

\subsection{Processo Desenvolvimento de Produto}

Atualmente existem diversos tipos de modelos de referência que podem ser utilizados para a definição do processo de desenvolvimento de produtos (PDP), entretanto o mais citado no âmbito acadêmico é o modelo proposto por Rozenfeld et al. (2006), que define o PDP como um modelo genérico mas que pode ser adaptável para a criação de modelos de referência específicos adequando-se à realidade da organização e ao produto, seja de bens de consumo duráveis ou de capital.

O conjunto de atividades pelas quais é composto o PDP busca solucionar as necessidades do mercado, enxergar oportunidades de negócio e alinhá-las com as estratégias do produto da empresa e suas restrições tecnológicas, com isso é possível obter as especificações do projeto do produto e de seu processo de produção (ROZENFELD et al., 2006, p.3). Sendo este conjunto de atividades o norte para o delineamento da prototipação do RentApp.

O modelo divide-se em três macrofases: Pré- Desenvolvimento, Desenvolvimento e PósDesenvolvimento, sendo estas subdivididas em fases e atividades, como pode ser visto na Figura 1 a seguir. 


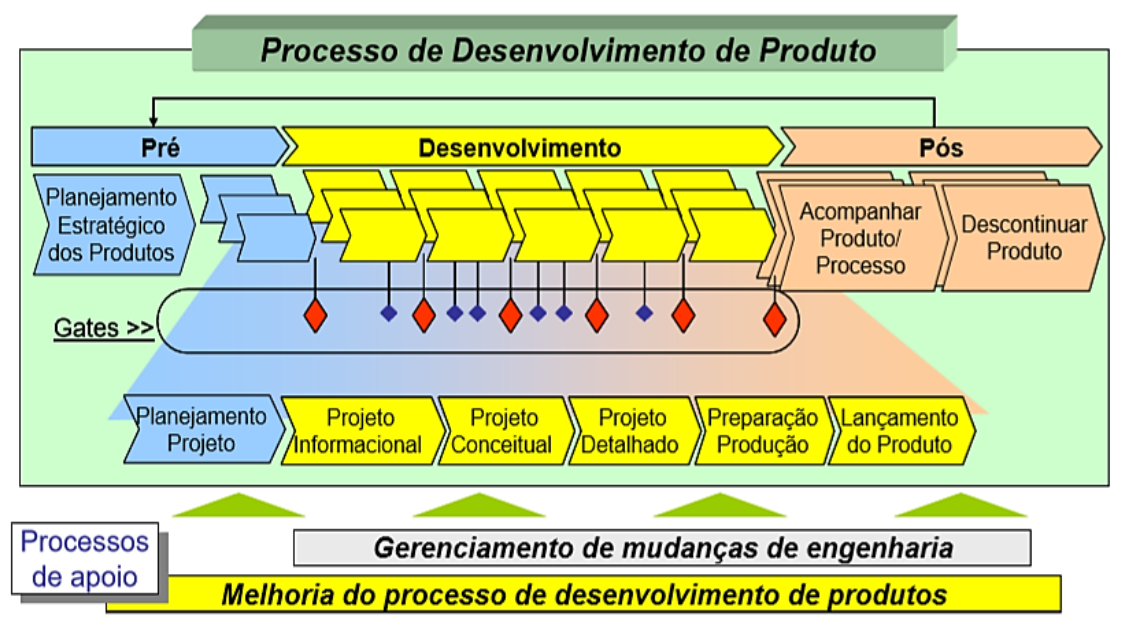

Figura 1. Modelo unificado de PDP (ROZENFELD, 2006, p.44).

Na Figura 1 é possível observar as três macrofases, que se desdobram em nove fases do PDP, e abrangem todo o ciclo de vida do produto. A macrofase de 'Pré-Desenvolvimento' conta com as fases de 'Planejamento Estratégico dos Produtos' e 'Planejamento do Projeto'. A macrofase de 'Desenvolvimento' é constituída pelas fases de 'Projeto Informacional', 'Projeto Conceitual', 'Projeto Detalhado', 'Preparação da Produção' e 'Lançamento do Produto'. A última macrofase é denominada 'Pós-Desenvolvimento', e constitui-se pelas fases de 'Acompanhar Produto/Processo' e 'Descontinuar Produto'.

O que determina uma fase é a entrega de resultados, ou seja, o final de uma fase é delimitado pela avaliação da mesma, através dos chamados gates, representados no modelo pelos losangos. É importante entender os conceitos de processo e projeto no modelo.

Rozenfeld et. al. (2006), define processo como "um conjunto de atividades organizadas entre si, visando produzir um bem ou um serviço para um tipo específico de cliente", que podem representar operações repetitivas, normalmente estruturadas, e com objetivos estabelecidos periodicamente. E o termo projeto é definido como conjunto de atividades únicas e temporárias, ou seja, possuem início, meio e fim, com objetivos únicos e específicos a serem atingidos.

A partir da fase de 'Planejamento de Projeto', as fases passam a ser representadas por múltiplos elementos gráficos, indicando que o 'processo' poderá conter mais de um ‘projeto'. Na prática, normalmente é o que acontece, visto que as empresas possuem um portfólio de produtos, cada um resultante de um projeto específico (BERGAMIN, FONSECA, NICKEL, 2015).

A etapa de Pós- Desenvolvimento é de extrema importância uma vez que os conhecimentos adquiridos ao longo das macrofases do desenvolvimento do produto serão sistematizados e 
documentados, a partir do registro de lições aprendidas, viabilizando sua reutilização em projetos futuros. Além disso, é feita uma avaliação de todo o ciclo de vida para determinar o grau de acerto ao longo das macrofases, assim é possível criar indicadores de desempenho para a empresa no desenvolvimento de futuros produtos.

\section{RESULTADOS E DISCUSSÃO}

\subsection{Planejamento estratégico do produto}

O planejamento estratégico do produto é definido como um processo cujo objetivo é planejar o desenvolvimento e a concretização dos produtos (SIDÉN et al., 2000; VDI, 1980). Esse processo inclui tanto o desenvolvimento de protótipos, quanto o planejamento da imersão do produto no mercado (ULRICH; EPPINGER, 2004; BRAUN, 2005).

Assim, com o aumento da competitividade entre as organizações e aumento das exigências do consumidor, o planejamento estratégico do produto apresenta um fator chave, uma vez que é possível através dele determinar se o desenvolvimento do novo produto irá de fato contribuir para o aumento da valorização da empresa e consequentemente aumentando sua participação no mercado (SIDÉN et al., 2000; LINDEMANN, 2003; COOPER, 2001).

\subsubsection{Conceito do produto}

O objetivo é desenvolver um aplicativo que tem como principal finalidade o consumo colaborativo, ou seja, o compartilhamento de produtos entre pessoas físicas ou jurídicas, inicialmente nas seguintes categorias: Máquinas e ferramentas, Esporte e lazer, Moda e acessórios, Festas e eventos, Multimídia e Instrumentos e equipamentos. O app foi denominado pelos pesquisadores de RentApp.

\subsubsection{Interface e funcionamento}


A plataforma apresenta dois tipos de usuários: Usuário vendedor (que deseja ganhar dinheiro alugando) e Usuário comprador (que somente deseja alugar algum tipo de item). Na Figura 2 abaixo, no centro, é possível observar a tela de cadastro dos compradores e vendedores, que será feita com as seguintes informações: Estado, cidade, foto, nome, CPF, e-mail e senha. Na mesma Figura 2 lado direito, o usuário seleciona no mapa o estado e cidade em que se encontra naquele momento, permitindo que os usuários vendedores e compradores possam ganhar alugando ou alugar aqueles itens que desejam mesmo sem estar no estado, cidade de origem.
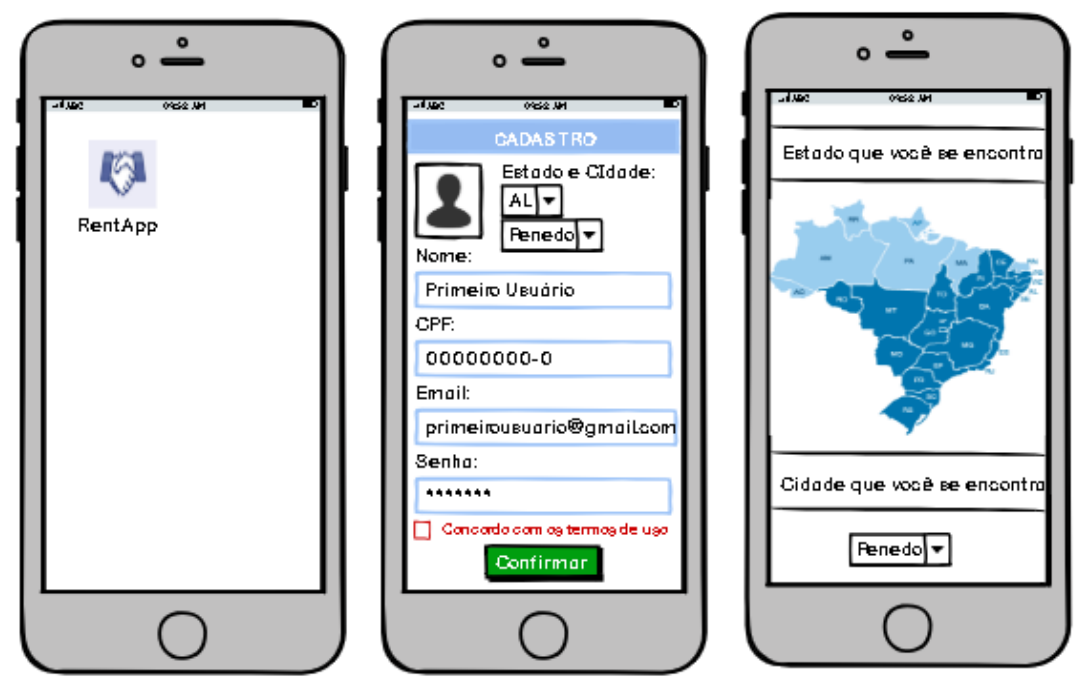

Figura 2. Primeiro acesso RentApp Cadastro de usuários.

Fonte: Próprio autor (2019).

Na Figura 3 seguinte, tela esquerda, o usuário tem acesso aos seguintes ícones: Alugar, ganhar alugando, ajustes e atendimento. Ao clicar em "Alugar", ainda na Figura 3 tela direita, o usuário será caracterizado como comprador, o mesmo pode prosseguir entre dois caminhos, ir para a aba "Categorias" ou "Buscar por palavra chave". 

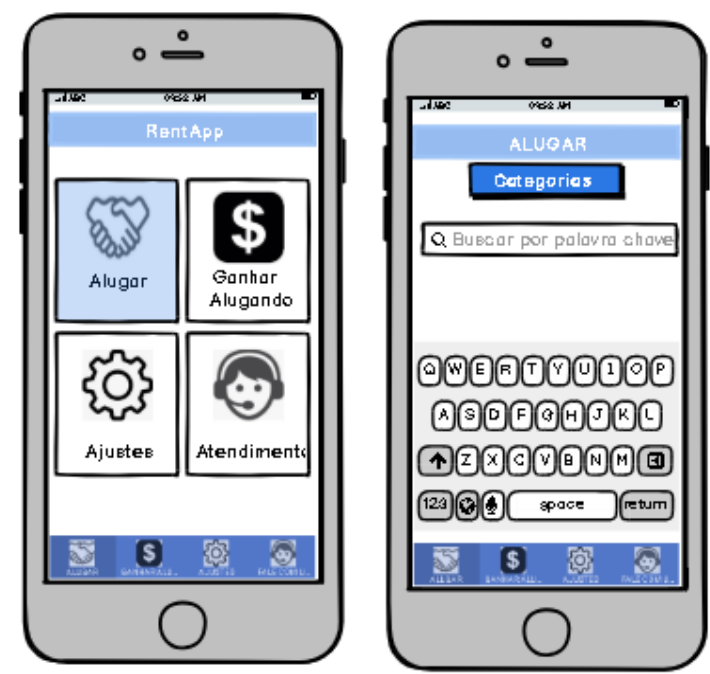

Figura 3. Tela principal RentApp aba “Alugar".

Fonte: Próprio autor (2019)

Ao clicar no ícone "Categorias", Figura 4 a seguir lado esquerdo, é possível observar todas as categorias disponíveis, que são elas: Máquinas e ferramentas, esporte e lazer, moda e acessórios, festas e eventos, multimídia e por fim instrumentos e equipamentos. Além disso, na parte inferior o usuário pode navegar de forma rápida clicando nos ícones; alugar, ganhar alugando, ajustes e atendimento.

Ainda na Figura 4 a seguir, no centro, após a escolha da categoria, o usuário comprador pode buscar diretamente o item pelo nome, como pode ser visto na parte superior ao lado direito no campo "Buscar", ou o mesmo pode apenas visualizar os diversos itens da categoria selecionada. O usuário comprador tem as seguintes informações; foto do produto, localidade, distância entre ele e o produto e o valor da diária, como pode ser visto para a furadeira industrial, kit ferramentas, serra mármore e lavadora industrial de piso.

Ao clicar no produto de interesse, como pode ser visto Figura 4 a seguir lado direito, o usuário comprador pode obter mais informações, como; foto do produto, estado de funcionamento (essa avaliação é feita pelos próprios usuários que já alugaram o produto), data de retirada, data de devolução, total a ser pago e escolher a forma de pagamento que desejar. 

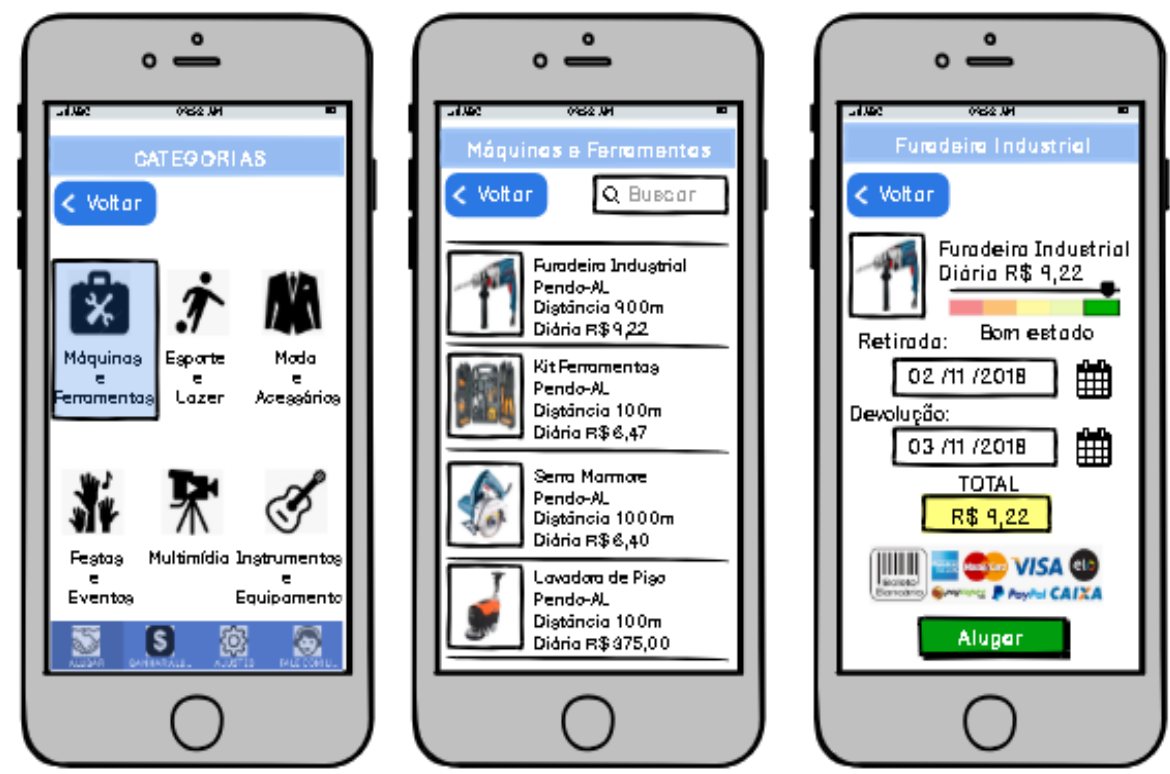

Figura 4. Categorias para alugar e pagamento.

Fonte: Próprio autor (2019).

Para os usuários vendedores, na Figura 5 a seguir tela esquerda, ao selecionar o campo "Ganhar alugando" o vendedor será encaminhado para as categorias do aplicativo, escolhendo assim a categoria em que o item a ser alugado se encaixa Figura 5 a seguir tela do lado direito.
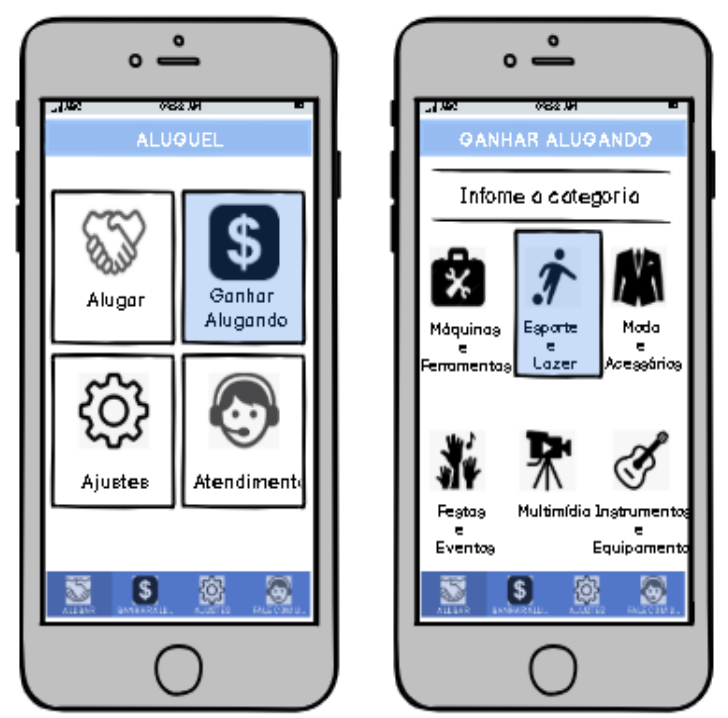

Figura 5. Tela principal RentApp aba "Ganhar Alugando".

Fonte: Próprio autor (2019).

Na Figura 6 seguinte lado esquerdo, para postar um item para aluguel é necessário escrever o título do anúncio e em seguida, Figura 6 seguinte lado direito, anexar fotos e informar o valor 
de compra do seu produto, assim o aplicativo faz o cálculo do valor da diária do aluguel, neste caso, estimado em $\mathbf{2 , 5 \%}$ do valor em que o produto é comercializado. $\mathrm{O}$ valor da diária cobrado pela plataforma levará em consideração a média do valor de aluguel feito por empresas que atuam no setor, assim o valor apresentará variação a depender do produto para que preço seja competitivo.
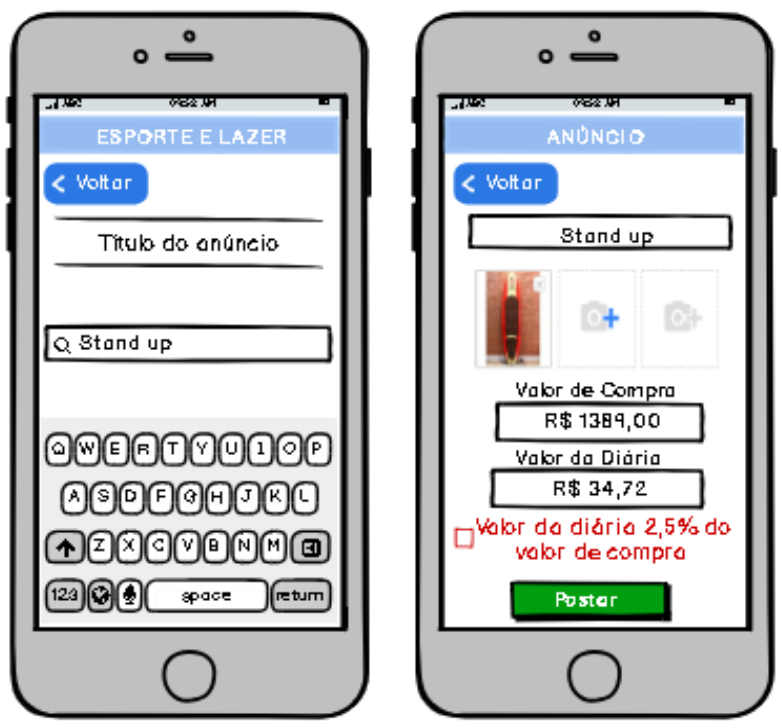

Figura 6. Criando um anúncio.

Fonte: Próprio autor (2019).

A seguir, na Figura 7, é possível observar o procedimento para que o cliente vendedor RentApp possa consultar o saldo em sua conta, resultado dos seus alugueis, bem como fazer a transferência desse valor para o banco de preferência.
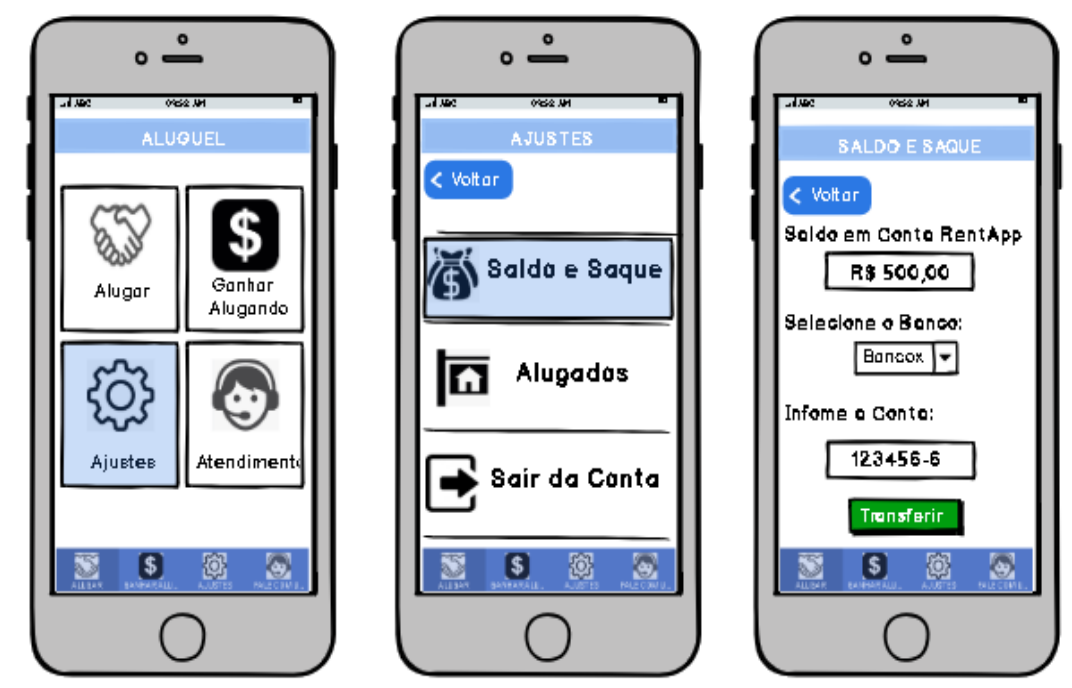

Figura 7. Tela principal RentApp aba "Ajustes" e "Saldo e Saque". 
Fonte: Próprio autor (2019).

$\mathrm{Na}$ Figura 8 seguinte, o cliente RentApp denominado comprador pode ter acesso aos itens que alugou e acompanhar o prazo que tem para devolver, após feita a devolução o item é automaticamente retirado da lista.
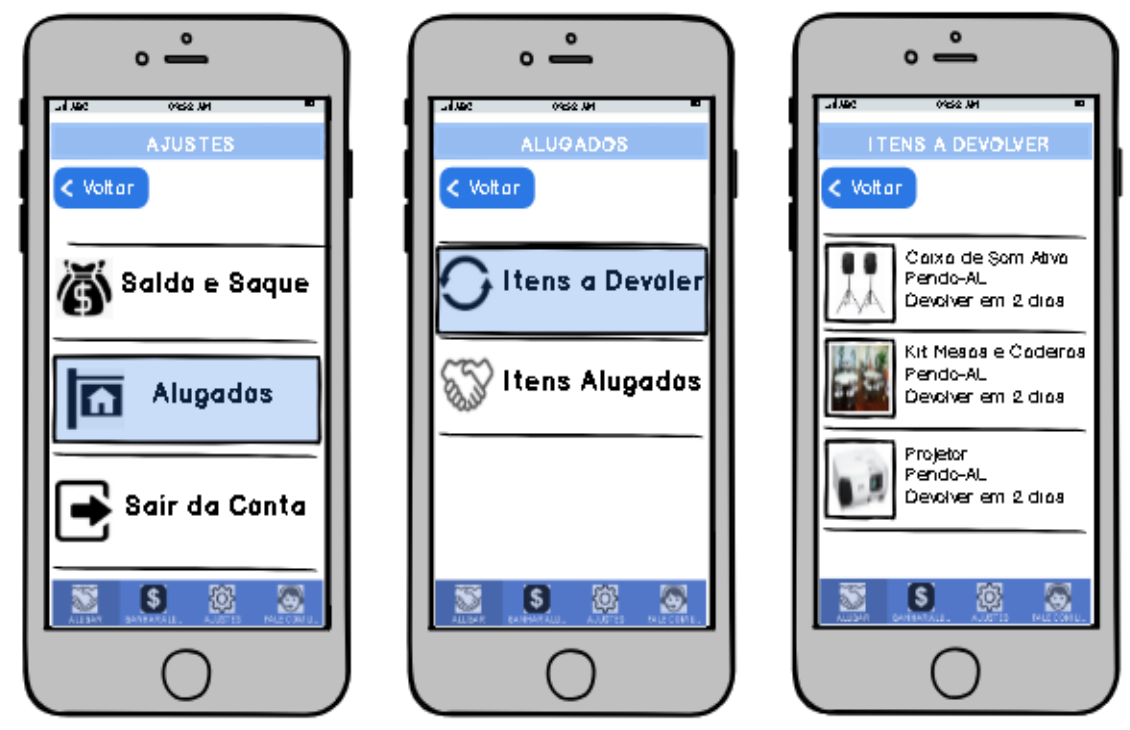

Figura 8. Tela principal RentApp aba "Alugados" e "Itens a Devolver "

Fonte: Próprio autor (2019).

Na Figura 9 seguinte será mostrado como o cliente RentApp denominado vendedor, pode ter acesso aos seus itens alugados, bem como o prazo que seu cliente tem para devolver.
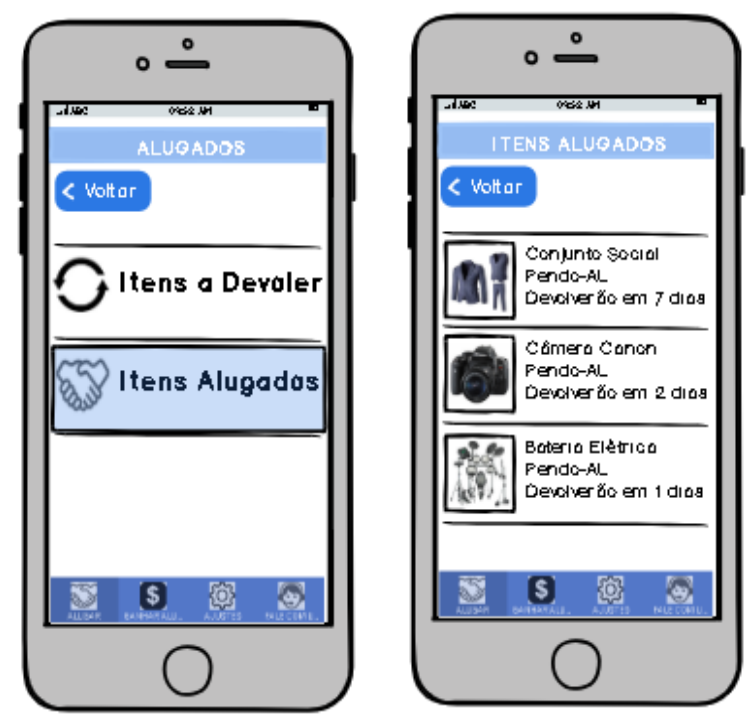

Figura 9. Tela principal RentApp aba "Alugados" e "Itens Alugados".

Fonte: Próprio autor (2019). 
O último ícone da tela principal é mostrada a seguir, Figura 10, a aba "Atendimento". Nela, compradores e vendedores podem entrar em contato com o serviço de atendimento ao cliente para tirar dúvidas e fazer reclamações. O contato com a RentApp pode ser feito de três formas; através de um chat online, por ligação ou via e-mail.

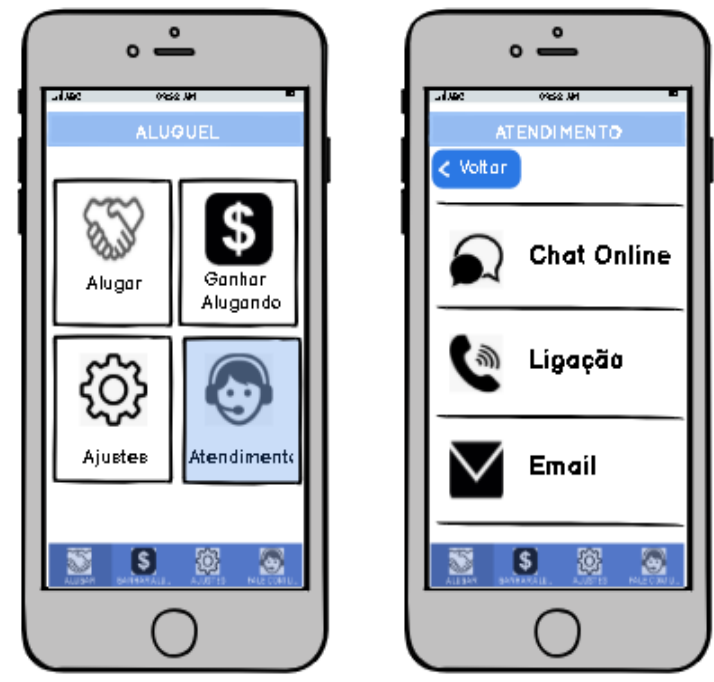

Figura 10. Tela principal RentApp aba "Atendimento".

Fonte: Próprio autor (2019).

Baseando-se nas fragilidades dos sites que oferecem o mesmo tipo de serviço, a RentApp buscou implementar melhorias que proporcionam um diferencial competitivo, como por exemplo; estabelecer políticas internas para cancelamento, prolongamento e adiantamento de utilização do produto, dentre outras. Por se tratar de característica de inovação, com o objetivo de preservação, os demais diferenciais não foram expostos neste trabalho, entretanto já foram prototipados.

\subsection{Análise de Tendência de Mercado e Prospecção Tecnológica}

O Brasil lidera a América Latina no uso de aplicativos com um PIB de R \$ 6,8 trilhões em 2018, entretanto o contexto econômico do país nos últimos anos não expressa boas perspectivas, o país precisa encontrar novas fontes de crescimento para ajudar a elevar os padrões de vida da população, especialmente saindo da recessão. Em 2017 o Brasil representava 312mil apps na Economia de Aplicativos (App Economy), o que pode ser uma rota importante para ganhos econômicos e de emprego. O crescente mercado doméstico de aplicativos demonstra que os desenvolvedores de aplicativos têm espaço no mercado. Um relatório de 2016 do World 
Economic Forum (WEF), aponta que o Brasil possui algumas vantagens que ajudam a apoiar seu crescente ecossistema de smartphone, como: as altas médias de uso do celular por indivíduo, os números de assinaturas de dispositivos celulares que crescem exponencialmente, além do expressivo uso da internet e as crescentes assinaturas de banda larga fixa (LEWIS, 2016; MANDEL; LONG, 2017).

A prospecção tecnológica do setor de TI no país também apresenta boas perspectivas e oportunidade de mercado para a criação de novas startups. Além disso, iniciativas governamentais tem propiciado um cenário animador, o Start-Up Brasil, Programa Nacional de Aceleração de Startups, é uma iniciativa do governo federal, criado pelo Ministério da Ciência, Tecnologia, Inovações e Comunicações (MCTIC), que desde 2012 seleciona e apoia as melhores empresas nascentes de base tecnológica, as startups; e contribui com a construção de um ambiente favorável à pesquisa, desenvolvimento e inovação em Tecnologias da Informação e Comunicação.

\subsection{Análise da Concorrência}

O mapeamento e análise da concorrência foram feitos em diversos sites que disponibilizam serviços similares, reportagens veiculadas em revistas e nas lojas online de aplicativos.

No contexto geral, os sites e aplicativos que oferecem serviços de aluguel para um ramo específico de mercado, são do ramo de imóveis (TechTudo, ZapImóveis, Airbnb), carros (Localiza, Hertz, Movida), roupas (Armário compartilhado), bicicletas (Spinlister, Grin) e até guia turístico (Rent a local friend), porém todos esses são específicos e únicos por categoria de aluguel.

Os dois sites que oferecem aluguel de produtos no contexto geral e se assemelham ao aplicativo proposto, são: 
- O Rent for All- que reúne produtos para locação anunciados tanto por pessoas físicas como por empresas;

- Alooga- que possibilita alugar objetos diversos, como câmeras fotográficas, sobretudos, luvas de boxe e até drones;

Os dois são sites não possuem aplicativos. Disponibilizam basicamente o mesmo serviço de locação, porém somente o Rent for All é destinado a pessoa física e jurídica.

Ao comparar os serviços que o RentApp pretende oferecer com os dois sites similares, verificou-se que nenhum deles contempla: imagens reais dos produtos, políticas internas para cancelamento, extensão ou redução dos prazos de utilização do produto. O que torna o RentApp mais robusto e com atributos exclusivos.

Diante do exposto, é possível inferir que não há aplicativos com propostas diferentes do mercado convencional, que contemplem desde a locação do produto até a entrega. Sendo os disponíveis seguimentados e restritos a uma única localidade.

\section{CONSIDERAÇÕES FINAIS}

O artigo propôs a realização de uma análise de viabilidade técnica para o desenvolvimento de um aplicativo mobile sob a perspectiva de PDP para o ramo de aluguéis. Observou-se que o aplicativo tem potencial para o mercado além de possuir características inovadoras, tendo em vista o ineditismo de funcionalidades, ferramentas e oferecimento de serviços em uma única plataforma.

Para as fases iniciais do percurso metodológico de análise da viabilidade técnica do aplicativo fez-se uso do modelo unificado do PDP associando suas fases ao escopo do protótipo do RentApp. No sentido de atender o contexto do protótipo, verificou-se que para o desenvolvimento da RentApp serão necessárias adaptações no modelo, no entanto a adoção das macrofases do modelo de PDP é fundamental para garantir um produto competitivo e assertivo. No planejamento estratégico do produto, foram realizadas análises de tendência de mercado, prospecção tecnológica e análise da concorrência. E nelas, foi possível verificar que o mercado de apps tem crescido significativamente. Além de constatar que, apesar de existirem dois outros sites com escopo similar, não existem no formato de app e não possuem políticas internas para 
cancelamento, extensão ou redução dos prazos de utilização do produto, entre outras especificidades que estarão presentes na RenApp, que como forma de preservação das características inovadoras, não foram expostas neste trabalho.

A fase de especificações do produto foi composta pelas definiçõos de requisitos, conceito do produto e regras de negócio. Com isto, foi possível elaborar a prototipação do RentApp, a partir da engenharia de requisitos, para futura execução pelo desenvolvedor do aplicativo.

Por fim, pode-se destacar como benefícios da implementação do aplicativo via modelo de PDP:

- Praticidade e facilidade visto que as principais informações estão acessíveis a qualquer instante e por qualquer meio que possua internet;

- Facilidade e possibilidade de aumentar a renda para pessoa física, uma vez que qualquer um pode ganhar alugando;

- Ferramenta de marketing para pessoa jurídica, uma vez que as empresas que alugam qualquer tipo de material, equipamento, etc; poderão expandir o alcance de seus serviços através do app.

No que se refere à prospecção tecnológica do RentApp, a proposta é de uma plataforma hibrida, que possibilita aos usuários dos sistemas operacionais Android e IOS, que representam juntos mais de $80 \%$ dos sistemas operacionais presentes nos celulares do Brasil, tenham acesso. De maneira geral a chance de retorno monetário do aplicativo é considerável, tendo em vista o custo inicial baixo e o alcance de mercado que o aplicativo pretende atingir. Além disso, a plataforma busca trazer funcionalidades que os concorrentes não apresentam e que de certa forma, fazem toda a diferença para o usuário que busca praticidade, preço baixo e iteração com o aplicativo.

Em estudos futuros, pretende-se: o desenvolvimento do aplicativo proposto pelo presente artigo; adaptar a metodologia proposta para o desenvolvimento de aplicativos; elaborar um plano de negócios e uma pesquisa de mercado.

\section{REFERÊNCIAS}

BRAUN, Thomas E. Methodische Unterstützung der strategischen Produktplanung in einem mittelständisch geprägten Umfeld. 2005. Tese de Doutorado. Technische Universität München. 
CHAUDHARY, S.; SHARMA, G. A Studyon Mobile-Commerce.Advances in Computer Science andInformation Technology (ACSIT), n 3; Vol. 2, p. 4, 2015.

CHRISTENSEN, C.M. The Innovator's Dilemma. Harvard Business School Press. 1997,

COOPER, Robert Gravlin; EDGETT, Scott J.; KLEINSCHMIDT, Elko J. Portfolio management for new products. 2001.

DEGUSTA, Michael. Are Smart Phones Spreading Faster than Any Technology in Human History? Business Report. 2012. Disponível em: $<$ https://www.technologyreview.com/s/427787/are-smart-phones-spreading-fasterthan-any-technology-in-human-history/. Acesso em: $02 \mathrm{dez} 2018>$.

FIGUEIREDO, Carlos MS; NAKAMURA, Eduardo. Computação móvel: Novas oportunidades e novos desafios. T\&C Amazônia, v. 1, n. 2, p. 21, 2003.

GERMANO, E. C.; SOUZA, C. A. Só mais uma startup no tema mobilidade humana. Revista brasileira de Casos de Ensino em Administração, v. 6, n. 1, p. 1-6, Jan/jun, 2016.

JUGEND, Daniel. Desenvolvimento de produtos em pequenas e médias empresas de base tecnológica: práticas de gestão no setor de automação de controle de processos. 2006. 167 p. 2006 . Tese de Doutorado. Dissertação (Mestrado em Engenharia de Produção)-Escola de Engenharia, Programa de Pós-Graduação em Engenharia de Produção, Universidade Federal de São Carlos, São Carlos.

LEWIS, Jeffrey. Brazil Finance Ministry Raises 2017 GDP Growth Forecast to 1.6\%. Wall Street Journal, agosto, v. 17, 2016.

LINDEMANN, Udo. Methods are networks ofmethods. In: DS 31: Proceedingsof ICED 03, the 14th InternationalConferenceonEngineering Design, Stockholm. 2003.

MCKINSEY GLOBAL INSTITUTE. Disruptive technologies: Advances that will transform life, business, and the global economy. McKensie Quarterly, v. 45, n. May, p. 1-176, 2013.

MORICOCHI, Luiz; GONÇALVES, José Sidnei. Teoria do desenvolvimento econômico de Schumpeter: uma revisão crítica. Informações Econômicas, São Paulo, v. 24, n. 8, p. 27-35, 1994.

NICKEL, Elton Moura; BERGAMIN, Georgia Scarabelot; FONSECA, Guilherme Silva. Desenvolvimento de um modelo de referência adaptado aos projetos de design industrial da Inventório-Empresa Júnior de Design e Moda da UDESC. 2015. Projetica, v. 6, n. 2, p. 73-85.

ROZENFELD et al. Gestão do Desenvolvimento de Produtos: Uma referência para a melhoria do processo. 1 ed. São Paulo: Saraiva, 2006.

SCHUMPETER, Joseph A. The theory of economic development. Cambridge, Harvard University. 1957.

SIDÉN, J.; LINDSTRÖM, P.; PAULI, M. Strategicproductplanning-A case studyexploringtheprocessand its development. In: International Design Conference-Design. 2000.

TURRIONI, J. B.; MELLO, C. H. P. Metodologia de Pesquisa em Engenharia de Produção: Estratégias, métodos e técnicas para condução de pesquisas quantitativas e qualitativas. Dissertação (Pós-Graduação em Engenharia de Produção). Universidade Federal de Itajubá - UNIFEI, 2012.

ULRICH, K. T.; EPPINGER, S. D. Product design anddevelopmet,3. ed. New York: McGraw-Hill, 2004.

VDI. Productplanning: Flow, termsandorganisation. vol. May 1980, ed. Düsseldorf: VDIVerlag, 1980.

WAKKA, Wagner. Games e países emergentes impulsionam mercado de apps em 2018. Canaltech. 2018. Disponível em: $<$ https://canaltech.com.br/apps/games-e-paises-emergentes-impulsionam-mercado-de-apps-em$\underline{2018-111586 />}$. 